\title{
The effect of surgery and radiotherapy on oncological outcomes in high-risk prostate cancer
}

\section{Yüksek riskli prostat kanserinde cerrahi ve radyoterapinin onkolojik sonuçlara etkisi}

Taha Numan Yıkılmaz, Erdem Öztürk, İsmail Selvi, Halil Başar

Dr. Abdurrahman Yurtaslan Onkoloji Eğitim ve Araştırma Hastanesi Ankara, Üroloji Departmanı

\section{ÖZET}

GİRIŞ ve AMAÇ: Yüksek riskli prostat kanseri hastalarında en iyi tedavi yaklaşımının ne olduğu, halen tartışmaya açık bir konudur. Önerilen tedavi yaklaşımları; cerrahi (radikal retropubik prostatektomi) veya radyoterapi (RT) + androjen deprivasyon tedavisi (ADT) dir. Çalışmamızda yüksek riskli prostat kanserinde cerrahi ve radyoterapinin onkolojik sonuçlarını karşılaştırdık.

YÖNTEM ve GEREÇLER: Ocak 2008-Haziran 2015 arasında kliniğimizde yüksek riskli prostat kanseri tanısıyla tedavi edilen 50 hasta retrospektif olarak incelendi. Açık radikal retropubik prostatektomi (RRP) yapılan 20 hasta cerrahi grubuna, RT+ADT tedavisi verilen 30 hasta radyoterapi grubuna dahil edildi. Gruplar tedavi sonrası takipte, biyokimyasal nüks (BKN), biyokimyasal nükssüz sağ kalım (BFSK), kanser spesifik sağ kalım (KSK) ve genel sağ kalım (GSK) açısından incelendi.

BULGULAR: Hastaların ortalama yaşı 65.9 (51- 83 aralığında), ortalama başlangıç PSA seviyeleri 24.2 (1- 94.9 aralığında) ve ortalama takip süresi 50.24 ay (6- 104 aralığında) olarak hesaplandı. Takip süresi cerrahi grupta 55.7 ay, RT grubunda 46.6 ay idi. Hasta yaşı, başlangıç PSA değeri ve klinik evre RT grubunda daha yüksek saptandı ancak anlamlı bir istatistiksel fark bulunmadı. Cerrahi grupta biyopsi ve prostatektomi patolojilerine göre; 4 (\% 20) hastada upgrading, 10 (\% 50) hastada downstaging gözlendi. Gleason patern 5 gözlenen 4 (\% 20) hastanın hepsinde BKN saptandı. Radyoterapi grubunda ise hiçbir hastanın biyopsisinde patern 5 saptanmadı.

TARTIŞMA ve SONUÇ: Literatürdeki pek çok çalışmaya benzer şekilde, bizim çalışmamızda da yüksek riskli prostat kanserinde RT+ADT uygulanan hastaların RRP uygulananlara göre, daha iyi onkolojik sonuçlar içerdiğini saptadik.

Anahtar Kelimeler: prostat kanseri, yüksek risk, radyoterapi, radikal prostatektomi

\begin{abstract}
INTRODUCTION: The best treatment approach is still a matter of debate in high-risk prostate cancer patients. Recommended treatment approaches are surgery (radical retropubic prostatectomy) or radiotherapy $(\mathrm{RT})+$ androgen deprivation therapy (ADT). In our study, we compared the oncological outcomes of surgery and radiotherapy in high-risk prostate cancer.
\end{abstract}

METHODS: Fifty patients who were treated with high-risk prostate cancer in our clinic were retrospectively studied between January 2008 and June 2015. Twenty patients with open radical retropubic prostatectomy (RRP) were included in the surgical group and 30 patients with RT + ADT therapy were included in the radiotherapy group. Groups were evaluated in terms of biochemical recurrence $(\mathrm{BCN})$, biochemical recurrence-free survival (BFSR), cancer-specific survival (CFS), and overall survival (GFS).

RESULTS: Mean age of the patients was calculated 65.9 (range 51-83), mean baseline PSA levels were 24.2 (range 1-94.9), and mean follow-up was 50.24 months (range 6-84). The follow-up period was 55.7 months in the surgical group and 46.6 months in the RT group. Patient age, initial PSA level and clinical stage were found higher in RT group but no significant statistical difference was found. According to biopsy and prostatectomy pathologies in the surgical group; $4(20 \%)$ patients were upgrading and $10(50 \%)$ patients were downstaging. Four patients $(20 \%)$ which observed Gleason pattern 5 was detected biochemical recurrence. No pattern 5 was detected in the biopsy of any patient in the radiotherapy group. 
DISCUSSION AND CONCLUSION: Similar to many studies in the literature, we found that patients treated with RT + ADT in high risk prostate cancer had beter oncologic outcomes than those with RRP.

Keywords: prostate cancer, high risk, radiotherapy, radical prostatectomy

\section{Giriş:}

Prostat kanseri erkeklerde tüm kanser türleri içerisinde, cilt kanserinden sonra ikinci sıklıkta görülen malign neoplazidir. 2013 yılında Amerikalı erkeklerde 238.590 kişide görüldüğü tahmin edilmektedir(1). Erkeklerdeki tüm kanserlerin \%28'ini oluşturmaktadır. Prostat spesifik antijen (PSA) testinin yaygın kullanımı ile prostat kanseri yakalanma oranları \%90'lara ulaşmaktayken olguların \%40'1 yüksek riskli prostat kanseri tanıs1 almaktadır (2). Prostat kanseri düşük, orta ve yükssek olmak üzere üç risk grubuna sinıflandırılır. Tanı anındaki PSA değeri $>20 \mathrm{ng} / \mathrm{ml}$ veya biyopsi Gleason skoru $\geq$ 8 veya klinik $\mathrm{T}$ evresi $>3$ a ise yüksek riskli prostat kanseri olarak sinıflandirılmaktadir(3).

Lokalize prostat kanserinin tedavisinde kesin bir ortak görüş olmamasına rağmen cerrahinin diğer tedavi seçeneklerine üstünlüğü gösterilmiştir ${ }^{1}$. Günümüzde radikal retropubik prostatektomi(RRP) erken evre, düşük riskli olgularda ilk tedavi seçeneği olarak karşımıza çıkmaktadır. Fakat yüksek riskli olgularda suboptimal PSA kontrolü ve sağ kalım oranları elde edilebilmektedir. Bu grup hastalarda, çoğu merkezde iki tedavi yaklaşımından biri seçilmektedir: cerrahi (RRP) veya radyoterapi $(\mathrm{RT})+$ androjen deprivasyon tedavisi (ADT) $(4,5)$.

Cerrahi tedavi uygulanan hastalarda ekstrakapsüler yayılım (EKY), seminal vezikül invazyonu (SVI), cerrahi sınır pozitifliği (CS+) ve lenf nodu tutulumu (N+)gibi patolojik sonuçlara rastlanabilmektedir(6,7). $\mathrm{Bu}$ da cerrahi sonrası RT gibi ek tedavilere ihtiyaç duyulmasına yol açmaktadır. Radyoterapi verilen yüksek riskli olgularda ise RT ve $A D T$ kombine tedavisi verilmekte ve bu tedavi 2-3 y1l kadar sürebilmektedir $(3,8,9)$. Özellikle Gleason skorunun fazla olduğu yüksek riskli olgularda hastal1k progresyonu ve kanser spesifik mortalite oranları artmaktadir $(10,11)$. Güncel olarak 2014' te International Society of Urological Pathology (ISUP) yeni bir Gleason derecelendirme sistemini kabul etmiştir. Buna göre yüksek riskli hastalar kendi arasında Gleason skor 8 ve Gleason skor 9-10 olmak üzere iki kategoriye ayrılmıştır. Gleason skor 910 daha kötü prognoz ile ilişkilendirilmiştir $(12,13)$. Bu da bize göstermektedir ki yüksek riskli prostat kanserinde en iyi tedavi yaklaşımının ne olduğu, halen tartışmaya açık bir konudur.

Literatürde pek çok çalışmada bu iki tedavi seçeneğinin onkolojik sonuçları karşılaştırılmıştır. Fakat prospektif, randomize kontrollü büyük hasta serilerini içeren çalışmalar halen yoktur. $\mathrm{Bu}$ nedenle tedavi modalitelerinin belirlenmesinde retropektif çalışmalar esas alınmaktadır. Biz de çalışmamızda Türk popülasyonunda yüksek riskli prostat kanserinin tedavisinde açı radikal retropubik prostatektomi ile RT+ADT tedavi yaklaşımlarının onkolojik sonuçlarını karşılaştırmayı amaçladık.

\section{Gereç ve Yöntemler:}

Kliniğimizde Ocak 2008-Haziran 2015 arasında yüksek riskli prostat kanseri nedeniyle tedavi edilen50 hasta çalışmaya alındı. Olguların 20 tanesine açı RRP, 30 tanesine ise RT+ADT kombinasyon tedavisi verildi. Tanı anında metastatik hastalık tanısı olan, 1 yıldan az takibi olan, neoadjuvanRT veya ADT alan veya hasta verileri yetersiz olan olgular çalışma dişı bırakıldı. Retrospektif olarak hastaların verileri incelendi. Radyoterapi verilen olguların tamamına eşzamanlı ADT başlandı. Radyoterapi öncesi 2 ay, RT ile eşzamanl 2 ay ve RT sonrası 3 yıla varan ADT (goserelin asetat) verildi. Radyoterapi verilen olgularda ise iki yöntem kullanıldı. Birinci yöntemde 3 boyutlu konformal RT (3D konformal RT) tekniğinde pelvik lenf nodlarına $1.8 \mathrm{~Gy}$ günlük fraksiyon dozunda 45-50 Gy RT, prostat ve seminal veziküllere 67 Gy (65.0-68.0 Gy) dozunda, toplam verilen doz <72 Gy olacak şekilde uygulandı. İkinci yöntem olan Intensitymodulated radiotherapy (IMRT) tekniğinde ise prostat ve pelvik lenfatik bölgeyi de içerecek 
şekilde 35-37 fraksiyonda toplam doz 72$81(\geq 72)$ Gy olacak şekilde uygulandi. Bu yöntem ile özellikle prostatın konkav şekilli hedef hacimlerinde, doz yoğunlukları ayarlanarak daha fazla etkinlik sağlanırken, çevre organlarda daha az yan etki oluşmaktadır. Her iki yöntemde de bölünmüş fraksiyonlar halinde 15 günlük tedavi uygulandı. Tedaviyi takip eden dönemde PSA seviyesinin nadir değerin $2 \mathrm{ng} / \mathrm{mL}$ üstüne çıkması nüks olarak değerlendirildi.

Cerrahi grubundaki olguların tümüne açık radikal retropubik prostatektomi ve bilateral genişletilmiş lenf nodu diseksiyonu uyguland1. Cerrahiler prostat biyopsilerinden en az 6 hafta sonra uyguland1. Cerrahi öncesi RT veya ADT alan olgular çalışma dış bırakıldı. Postoperatif dönemde PSA değeri 0,2 ng/mL üstüne çıkan olgularda biyokimyasal nüks (BKN) varlığı kabul edildi. Tüm patoloji spesmenleri üropatolog tarafindan değerlendirildi.

Primer tedavilerinin ardından olgular ilk 2 y1l 3 ayda bir, sonra 6 ayda bir PSA ile takip edildi. Olguların hastalıksız sağkalım ve biyokimyasal nüksleri (BKN) değerlendirilerek gruplar karşılaştırıldı.

Çalışma retrospektif olarak dizayn edilmiş olup cerrahi öncesi aydınlatılmış onay formu alınmış ancak etik komite onay alınmamıştır. İstatistiksel analizler SPSS 21,0 versiyonu (SPSS inc. Chicago, IL, USA) kullanılarak gruplar arası Pearson ki-kare testi ile yapıld1. $p$ değeri 0,05 'in altındaki değer anlamlı kabul edildi.

\section{Bulgular:}

Kliniğimizde Ocak 2008 ile Haziran 2015 arasında prostat kanseri nedeniyle cerrahi veya $\mathrm{RT}+\mathrm{ADT}$ tedavisi verilen olguların verileri retrospektif olarak taranarak yüksek riskli prostat kanseri tanısı konulan 50 olgu çalışmaya alındı. Olguların demografik özellikleri, klinik ve patolojik bulguları gruplandırılarak karşılaştırıldı. Olgular cerrahi ve RT grubu şeklinde 2 gruba ayrildı. Tüm olguların ortalama yaşı 65.9 (51-83 aralığında), ortalama başlangıç PSA seviyeleri 24.2 (1- 94.9 aralığında) ve ortalama takip süresi 50.24 ay (6104 aralığında) şeklinde bulundu. Takip süresi cerrahi grupta 55.7 ay, RT grubunda 46.6 ay idi. Hasta yaşı, başlangıç PSA değeri ve klinik evre
RT grubunda daha yüksek saptandı ancak anlamlı bir istatistiki fark bulunmadı.

Cerrahi grubun biyopsi ve prostatektomi patolojileri karşılaştırıldığında, 4 (\% 20) hastada upgrading, $10(\%$ 50) hastada ise downstaging gözlendi. 4 (\% 20) hastada hem biyopsi hem de prostatektomi patolojilerinde Gleason patern 5 gözlendi ve bu hastaların hepsinde BKN saptand1. Bir hastada ise biyopsi sonucu Gleason $3+5$ iken prostatektomi sonucu Gleason $3+4$ olarak saptand1. Downstaging olarak değerlendirilen bu hastada BKN gözlenmedi. Radyoterapi grubunda ise hiçbir hastanın biyopsisinde patern 5 saptanmad. (Tablo 1)

Cerrahi grupta 12 kor biyopside ortalama pozitif kor sayıs 5.89iken, BKN gözlenmeyenlerde 3.75 , BKN gözlenenlerde 7.44olarak saptand1. Radyoterapi grubunda ise, 12 kor biyopside ortalama pozitif kor sayıs 5.91 iken BKN gözlenmeyenlerde 4.23, BKN gözlenenlerde 6.01 bulundu. (Tablo 1)

Radyoterapi grubunda 30 hastanın $9(\%$ 30)' una $<72$ Gy dozda 3D konformal RT, 21 (\% 70) hastaya ise $\geq 72$ Gy dozda IMRT uygulandı. Bu grupta BKN gözlenen 3 (\% 10) hastanın ikisine 3D konformal RT, birine ise IMRT uygulandi.

Hormon tedavisi RT grubundaki tüm hastalara uygulanırken, cerrahi grupta patolojik $\mathrm{N}+$ saptanan $2(\%$ 10) hastaya adjuvan olarak uygulandi. Cerrahi sonrasında cerrahi sinır invazyonu olan $(\mathrm{CSI}+)$, ekstrakapsüler yayılımı olan (EKY) ve seminal vezikül invazyonu (SVI) saptanan toplamda 6 (\% 30) hastaya cerrahiyi takiben ilk 6 ay içerisinde adjuvan RT planlandi. Ortalama 24.6 aylık takipte, bu hastaların ikisinde adjuvan RT sonrasında BKN gözlenmezken, diğer 4 hastada ise postoperatif morbidite düzelip RT başlanana kadar geçen 3 ay içerisinde BKN saptandi. Cerrahi sonrası CS+, EKY ve SVI içermeyen 14 (\% 50)hastanın ortalama 27.4 aylık takibinde $7(\% 35)$ hastada BKN gözlendi ve salvaj RT uygulandı. Hastalıksız sağkalım analizinde cerrahi grupta 18.1 ay ( $10-31$ ay), RT grubunda ise 45.1 ay (6 - 104) sağkalım görüldü. İstatistiksel olarak anlamlı görülen bu sonuç ile RT alan olguların BKN gelişme süresi daha geç olarak tespit edildi. Cerrahi grupta hastalıksız sağ kalım süresi 18.1 ay (10-31 aralığında) iken; radyoterapi grubunda 45.1 ay (6-104 aralığında) olarak hesaplandi. (Tablo 1) 
Tablo 1: Olguların gruplar halinde karakteristik özellikleri

\begin{tabular}{|c|c|c|}
\hline & Cerrahi & Radyoterapi \\
\hline Hasta sayıs1 (n) & 20 & 30 \\
\hline Yaş ortalaması (yıl) & 61.55 & 68.8 \\
\hline Ortalama PSA değeri (ng/mL) & 16.58 & 29.28 \\
\hline PSA $<10$ hasta sayıs1 (n) & 9 & 6 \\
\hline PSA $10-20(n)$ & 5 & 3 \\
\hline $\mathrm{PSA}>20(\mathrm{n})$ & 6 & 21 \\
\hline Preop klinik evre $\geq T 3$ (n) & 7 & 8 \\
\hline Biyopsi Gleason skoru (ortalama) & 7.75 & 7.56 \\
\hline $\begin{array}{l}\text { Biyopside ortalama pozitif kor sayısı (tüm } \\
\text { hastalar) }\end{array}$ & $5.89 / 12$ & $5.91 / 12$ \\
\hline $\begin{array}{l}\text { Biyopside ortalama pozitif kor sayısı (BKN } \\
\text { gözlenmeyenler) }\end{array}$ & $3.75 / 12$ & $4.23 / 12$ \\
\hline $\begin{array}{l}\text { Biyopside ortalama pozitif kor sayısı (BKN } \\
\text { gözlenenler ) }\end{array}$ & $7.44 / 12$ & $6.01 / 12$ \\
\hline Biyopsi Gleason Skor 8 (n) & 11 & 8 \\
\hline Biyopsi Gleason Skor 9-10 (n) & 3 & 7 \\
\hline Biyopsi Gleasonpatern 5 (n) & 5 & - \\
\hline Cerrahi Gleason skoru & 7.55 & - \\
\hline Cerrahi Gleason Skor 8 (n) & 6 & - \\
\hline Cerrahi Gleason Skor 9-10 (n) & 3 & - \\
\hline Cerrahi Gleason patern 5 (n) & 4 & - \\
\hline Cerrahi sınır pozitifliği (n) & 5 & - \\
\hline Ekstrakapsüler invazyon (n) & 4 & - \\
\hline Seminal vezikül invazyonu (n) & 5 & - \\
\hline Lenf nodu tutulumu (n) & 2 & - \\
\hline 3D konformal RT (n) & - & 9 \\
\hline $\operatorname{IMRT}(\mathrm{n})$ & - & 21 \\
\hline Ortalama takip süresi (ay) & 55.7 & 46.6 \\
\hline Biyokimyasal nüks oranı & $\% 55(\mathrm{n}: 11)$ & $\% 10(\mathrm{n}: 3)$ \\
\hline Hastalıksız sağkalım (ay) & $18.1(10-31)$ & $45.1(6-104)$ \\
\hline
\end{tabular}




\section{Tartışma:}

Cerrahi, RT ve brakiterapi (BT) günümüzde özellikle düşük riskli prostat kanserinde kabul edilen tedavi seçenekleridir ve bu tedavilerde yaşam kalitesi ve toplam sağ kalım açısından birbirlerine yakın sonuçlar elde edilmektedir. Ancak yüksek riskli lokalize prostat kanserinde durum farklıdır ve standart tedavi yaklaşımı halen net değildir. Yüksek riskli prostat kanserinde daha kötü hastalık kontrolü ve sağ kalım sonuçları bildirilmektedir. $\mathrm{Bu}$ grupta RRP uygulanan hastalarda çoğu kez SVI, EKY, $\mathrm{CS}+$ nedeniyle adjuvan RT verilmesi gerekmektedir. Çeşitli çalışmalar postop dönemde erken uygulanan adjuvan RT' nin daha iyi PSA kontrolü ve KSK sağladığını bildirmektedir(14,15). Hatta erken uygulanan salvajRT'nin bile daha iyi onkolojik sonuçlar içerdiği vurgulanmaktadır(16). Cerrahi sonrası LN tutulumu saptanan hastalarda ise subklinikmetastatik hastalık progresyonunu önleyeceği için adjuvan ADT önerilmektedir. Southwest Oncology Group (SWOG) çalışmasında RRP sonrası ilk 4 ay içerisinde başlanan RT' nin, BKN olunca başlanan salvaj RT'ye göre daha iyi hastalık kontrolü sağladığ 1 belirtilmektedir(14).

Watkins ve ark. yüksek riskli prostat kanseri tedavisinde 5 yıllık BKN oranını RT +ADT alanlarda \% 25.2, RRP uygulananlarda $\% 79.4$ olarak buldu. Aradaki bu ciddi farklilik, RRP uygulanan hastaların küçük bir yüzdesine adjuvan RT verilmesine bağlandı(17). Bu oranlar Baker ve ark.' nın çalışmasında ise sirasiyla \% 7.2 ve \% 42.3 bulundu(5). Ancak Watkins ve ark. BKN gelişmesi üzerine salvaj RT verilen hastaları biyokimyasal başarısızlık olarak belirtirken, Baker ve ark. bu hastaları başarısızlık olarak değerlendirmedi, salvaj RT tamamlandiktan sonra PSA relaps1 gözlediklerini biyokimyasal başarısızlık olarak sinıflandırdı. Baker ve ark. yüksek riskli hastalara RT+ADT verilmesinin

PSA nüksünü azaltmanın yanı sıra, bu hastaları RRP ve postop RT' nin getireceği yan etkilerden koruyacağını da savunmaktadır. Benzer çalışmalarda 5 yıllık BKN ve uzak metastaz görülme oranları RT + ADT grubunda cerrahi uygulananlara göre daha düşük saptandı(5). Bizim çalışmamızda ise cerrahi grupta 11 hastada (\% 55), RT grubunda ise 3 hastada (\% 10) BKN görüldü. Olguların hastalıksız sağkalımları cerrahi grupta 18.1 ay (10 - 31 ay), RT grubunda ise 45.1 ay $(6-104)$ olarak sonuçlanarak RT alan olguların BKN gelişme süresi daha geç olarak hesaplandı.

Verilecek RT dozunu belirlemek için pek çok çalışma yapılmıştır. Aizer ve ark. RRP ile IMRT $(\geq 72$ Gy)+ADT seçeneklerini karşılaştırdıkları 556 hastalık çalışmalarında, yüksek riskli grupta RRP' de \% 38.4' e karşılık IMRT+ADT' de \% 62.2 oranı ile daha yüksek biyokimyasal nükssüz sağ kalım (BFSK) gözlendi(18). Bu sonuçlar IMRT dozunun $\geq 72$ Gy olmas1 yanında, hastalara ek olarak ADT verilmesine de bağland1. Kupelian ve ark. verilecek RT dozunun biyokimyasal nükste etkili olduğunu belirtti. Orta ve yüksek risk grubunda $\geq 72$ Gy dozda uygulanan External beam radiationtherapy (EBRT)' nin RRP' ye göre daha yüksek BFSK avantajı yarattığını; oysaki < 72 Gy dozda EBRT' nin RRP' ye göre istatistiksel olarak daha düşük BFSK yarattığını gösterdi(19). Bizim çalışmamızda da literatürdeki yayınlara benzer şekilde, RT+ADT grubunda $<72$ Gy dozda 3D konformal RT uygulanan 9 hastanın ikisinde (\% 22) BKN gözlenirken, $\geq 72$ Gy dozda IMRT uygulanan 21 hastanın sadece birinde (\% 4) BKN gözlendi. $\mathrm{Bu}$ durum uygulanan RT dozunun etkinliğinin arttıkça, hastalık kontrolü ve BKN' ü önlemede başarılı olunduğunu göstermektedir.

International Society of UrologicalPathology' nin 2014'te yenilediği Gleason skor tanımlamasına göre Gleason skor 9-10, Gleason skor 8'den ayrıldı ve daha yüksek riskli sinif olarak tanımland. Kishan ve ark.' nın bu yeni tanımlamaya göre sadece Gleason skor 9-10'u içeren 487 hastalık retrospektif çalışmasında, hastalar EBRT, doz artırılmış radyoterapi $(\mathrm{EBRT}+\mathrm{BT})$ ve RRP kollarına ayrildı. Radyoterapi verilen her iki kolda da toplamda hastaların \% 94' üne ek olarak ortalama 24 ay kolda ise ADT sadece lenf nodu tutulumu $(\mathrm{N}+)$ saptanan hastalara uygulandi. Bizim çalışmamızda da benzer şekilde ADT kullanımı olduğu görülmektedir. Sağ kalım süreleri her üç kolda da aynı iken, EBRT+BT' nin daha iyi sistemik kontrol (metastazsız sağ kalım) sağlandığı gözlendi. Sonuç olarak Gleason 9-10' u içeren mikrometastaz açısından yüksek riskli grupta, optimal lokal kontrol için doz artırılmış RT' nin (EBRT+BT) kullanımını ve sistemik kontrol için ADT'nin kullanımını kapsayan EBRT+BT+ADT tedavisinin en iyi 
hastalık kontrolünü sağlayacağı gösterildi (20). Bizim çalışmamızda ise ISUP' un bu yeni derecelendirme sistemi dikkate alındığında, biyopsi sonucuna göre Gleason skor 8 olan hastaların \% 57.8' ine RRP, \% 42.2' sine RT+ADT uygulanırken; bu oran Gleason skor 9-10 olanlarda sirasiyla $\% 30$ ve $\% 70$ bulundu. $\mathrm{Bu}$ da daha yüksek riskli hastalarda tedavi tercihi olarak RT'nin ön planda olduğunu göstermektedir. Ama bu grupta hasta yaşının RRP' ye göre daha yüksek olması da bir yandan komorbid faktörler varlığında cerrahinin getireceği morbiditelerden kaçınıldığı şeklinde bir yaklaşım olduğunu da göstermektedir.

European Association of Urology (EAU), European Society for Radiotherapy \& Oncology (ESTRO), International Society of Geriatric Oncology (SIOG) ve National Comprehensive Cancer Network (NCCN) k1lavuzlarında yüksek riskli grupta RRP yapılsa bile adjuvan RT veya salvaj RT' yi içeren multimodal yaklaşım önerilmektedir(3,21). Nitekim büyük hasta sayılı son çalışmalarda RRP sonrası hastaların \% 12.4' ünde adjuvan RT uygulandığı, kalan hastaların ise BKN gelişince $\% 80$ ' inde salvaj RT verildiği bildirildi(3,21). Ancak bahsedilen çalışmada multimodal yaklaşıma uygun olarak gruplar arası eşit dağılım olmadığından RRP+ adjuvan/salvaj RT' nin EBRT+ADT grubuna veya $\mathrm{EBRT}+\mathrm{BT}+\mathrm{ADT}$ grubuna üstünlüğünü değerlendirip sonuçları genelleştirmek uygun değildir. Gruplar arasında tedavinin uygulanabilirlik oranı sirasıyla \% 84.1, \% 48.3 ve \% 60.9 bulundu. Bizim çalışmamızda ise, hasta sayıları açısından daha homojen bir dağılım gerçekleştiği görülmektedir. RRP sonras $1 \% 30$ hastaya adjuvan RT planlanırken, BKN gelişen tüm hastalara (grubun \% $35^{\prime}$ i) salvaj RT uyguland. Kishan ve ark. RRP hastalarının \% 55' nin bir şekilde adjuvan/salvaj RT aldığını saptarken, bizim hastalarda bu oran $\% 65$ bulundu(20).

\section{Kaynaklar}

1. Ucer $\mathrm{O}$, Muezzinoglu T. Yüksek riskli prostat kanserinde cerrahinin yeri. Bull Urooncol 2014; 13: 21-24

2. Kuzgunbay B, Yaycioğlu Ö. The role of radical prostatectomy for the treatment of patients with high risk prostate cancer. Journal of Urological Surgery, 2015; (3):120-123
Çalışmamızda tüm hastaların ortalama takip süresi 50.24 ay olup bu oran tedaviler aras1 mortalite sonuçlarını kıyaslamak için yeterli değildir. Ayrıca RT grubunda tüm hastalara rutin olarak 24 ay ADT verilmesi metastatik hastalık gelişimini geciktirirken, RRP yapilanlarda lenf nodu tutulumu olmayan hastalara ADT verilmediğinden hormon tedavisinin RRP üzerine olabilecek olumlu etkileri öngörülememektedir. Ancak literatürdeki çoğu çalışmada da bu eksiklik mevcuttur. Benzer şekilde kombine RT+ADT tedavisinin sadece RT üzerine üstünlüğünün olup olmadığını gözlemlemek de bu çalışma yapısında mümkün değildir. Çalışmamızın diğer kısıtlı yanları; retrospektif oluşu, hasta sayısının az olması, ortalama takip sürelerinin azlığı ve takipteki hastaların hiçbirisinde ölüm olmaması nedeniyle sağkalım analizleri yapılamamasidır.

\section{Sonuçlar}

Yayınlanmış pek çok çalışmaya benzer şekilde, bizim çalışmamızda da yüksek riskli prostat kanserinde $\mathrm{RT}+\mathrm{ADT}$ uygulanan hastaların RRP uygulananlara göre, BKN oranları ve hastalıksız sağkalım açısından daha olumlu sonuçlar içerdiğini saptadık. Özellikle RT dozunun artırıldığı IMRT tedavisine ilaveten ADT en iyi hastalık kontrolünü sağlamaktadır. RRP ise tek başına tedavi başarısı sağlayamamakta hastaların \% 65'i er ya da geç ilave RT tedavisine ihtiyaç duymaktadır. Bu durum bize, yüksek riskli hastalarda hangi yöntemi seçersek seçelim multimodal yaklaşımın önemini vurgulamaktadır.

Çıkar Çatışması: Yok
3. National Comprehensive Cancer Network. Prostate Cancer Guidelines (Version1.2015), 2015

4. Walsh PC, DeWeese T, Eisenberger MA. Localized prostate cancer. N Engl J Med 2007;357:2696-2705.

5. Baker CB, McDonald AM, Yang ES, Jacob R, Rais-Bahrami S, Nix JW et al. Pelvic radiotherapy versus radical prostatectomy with 
limited lymph nodes ampling for high-grade prostate adenocarcinoma. J Korean Med Sci,2016; Article ID 2674954, 8 pages

6. Makarov DV, Trock BJ, Humphreys EB et al. Updated nomogram to predict pathologic stage of prostate cancer given prostate-specific antigen level, clinical stage, and biopsy Gleason score (Partin tables) based on cases from 2000 to 2005. Urology 2007,69:10951101

7. Oefelein MG, Grayhack JT, McVary KT. Survival after radical retropubic prostatectomy of men with clinically localized high grade carcinoma of the prostate. Cancer 1995,76:2535-2542

8. Horwitz EM, Bae K, Hanks GE et al. Ten-year follow-up of radiation therapy oncology group protocol 92-02: a phase III trial of the duration of elective androgen deprivation in locally advanced prostate cancer. J ClinOncol 2008,26:2497-2504

9. Bolla M, Van Tienhoven G, Warde P et al. External irradiation with or without long-term androgen suppression for prostate cancer with high metastatic risk: 10-year results of an EORTC randomised study. Lancet Oncol 2010,11:1066-1073

10. P. C. Albertsen, J. A. Hanley, and J. Fine, “20Year outcomes following conservative management of clinically localized prostate cancer," The Journal of the American Medical Association, 2005,293: 2095-2101

11. P. Zhou, M.-H. Chen, D. McLeod, P. R. Carroll, J. W. Moul, and A. V. D'Amico, "Predictors of prostate cancer-specific mortality after radical prostatectomy or radiationtherapy," Journal of Clinical Oncology, 2005, 23: 6992-6998

12. Epstein JI, Egevad L, Amin MB, Delahunt B, Srigley JR, Humphrey PA. The 2014 International Society of Urological Pathology (ISUP) Consensus Conference on Gleason Grading of Prostatic Carcinoma: Definition of grading patterns and proposal for a new grading system. Am J SurgPathol 2016;40:244-52

13. Epstein JI, Zelefsky MJ, Sjoberg DD, et al. A contemporary prostate cancer grading system: A validated alternative to the Gleason Score. EurUrol 2016;69:428-35

14. ThompsonIM, Tangen $\mathrm{CM}$, Paradelo $\mathrm{J}$ et al. Adjuvant radiotherapy for pathological T3N0M0 prostate cancer significantly reduces risk of metastases and improves survival: longterm follow up of a randomized clinical trial. J Urol2009,181:956-962

15. Bolla $M$, van Poppel $H$, Collette $L$ et al. Postoperative radiotherapy after radical prostatectomy: a randomised controlled trial (EORTC trial 22911). Lancet 2005,366:572578

16. Fossati N, Karnes RJ, Cozzarini $C$, et al. Assessing the optimal timing for early salvage radiation therapy in patients with prostatespecific antigen rise after radical prostatectomy. EurUrol 2016;69:728-33

17. Watkins JM, Watkins PL, Dufan TA, Koleilat N. High-grade prostate adenocarcinoma (Gleason Score $\geq 8)$ : survival and disease control following radical prostatectomy versus radiotherapy plus long-course hormone therapy. J RadiatOncol 2015,4:277-282

18. Aizer AA, Yu JB, Colberg JW, McKeon AM, Decker RH, Peschel RE. Radical prostatectomy vs. intensity-modulated radiation therapy in the management of localized prostate adenocarcinoma. RadiotherOncol. 2009;93:18591

19. Kupelian PA, Elshaikh M, Reddy CA, Zippe C, Klein EA. Comparison of the Efficacy of Local Therapies for Localized Prostate Cancer in the Prostate- Specific Antigen Era: A Large SingleInstitution Experience With Radical Prostatectomy and External-Beam Radiotherapy. J ClinOncol 2002,20:3376-85

20. Ellis CL, Partin AW, Han M, Epstein JI. AdenocarcinomaoftheprostatewithGleasonscore 9-10 on corebiopsy: Correlationwithfindings at radicalprostatectomyandprognosis. J Urol 2013;190:2068-73

21. Mottet N, Bellmunt J, Briers E, et al. EUAESTRO-SIOG Guidelines for Prostate Cancer 2016 [cited 2016 May 21]. http://uroweb.org/ wp-content/uploads/EAU-Guidelines-ProstateCancer-2016.pdf 